
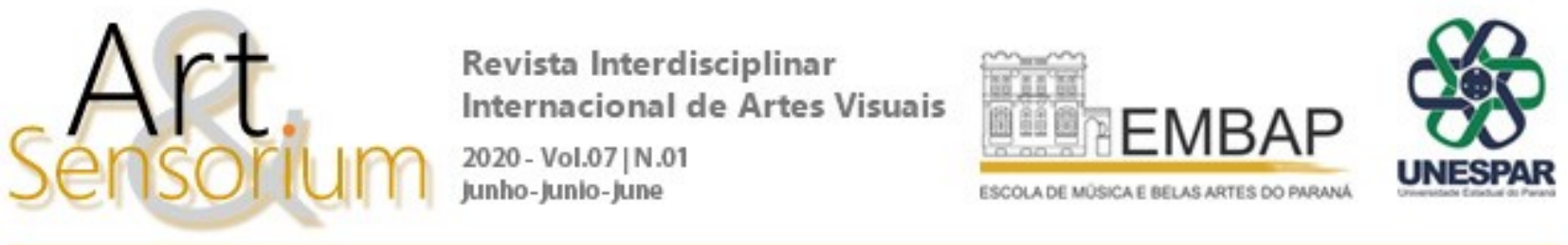

\title{
MUSEUS VIRTUAIS E GAMEARTE: SOBREVIVÊNCIAS DA ARTE EM ASSASSIN'S CREED 2 \\ DOI: https://doi.org/10.33871/23580437.2020.7.1.258-269
}

\section{Leonardo Ribeiro Brandão ${ }^{1}$ Antonio Vargas ${ }^{2}$}

RESUMO: Diferenciando os conceitos de Arte para Games, Gamearte, Artgames e Jogos de artistas o artigo discorre sobre a presença de reproduções de obras de arte renascentistas no jogo Assassin's Creed 2, e relaciona o uso de puzzles como uma estratégia dos criadores, a qual induz o jogador a fazer um processo semelhante ao proposto pelo historiador Aby Warburg. Os autores estabelecem esta relação fundamentando-a nos conceitos de Gamearte e Arte para games, identificam anacronismos imagéticos, estabelecem relações da experiência artística no jogo digital com outros relatos e possibilidades do imaginário e analisam em detalhe alguns dos puzzles existentes no game. Os autores ainda procuram destacar que a alta qualidade das reproduções gráficas das obras da Itália do século XV buscam provocar e/ou despertar nos jogadores uma familiaridade com os temas da História e da História da Arte referentes a este período.

Palavras-chave: Assassin's Creed; Pathosformel; Renascimento; Museu virtual; Arte em games

\section{VIRTUAL MUSEUMS AND GAMEART: ARTISTIC SURVIVALS IN ASSASSIN'S CREED 2}

\begin{abstract}
Differentiating the concepts of Art for Games, Gameart, Artgames and Artist's Games, the article discusses the presence of reproductions of Renaissance works of art in the game Assassin's Creed 2 , and relates the use of puzzles as a strategy of the creators, which induces the player to do a process similar to that proposed by the historian Aby Warburg. The authors establish this relationship by basing it on the concepts of Gameart and Art for games, identify anachronisms of imagery, establish relationships between the artistic experience in the digital game with other stories and possibilities of the

${ }^{1}$ Leonardo Ribeiro Brandão é graduado em Teatro (Licenciatura e Bacharelado) pela UDESC (Universidade do Estado de Santa Catarina) e mestrando no programa de pós-graduação em Artes Visuais da UDESC na linha de Teoria e História das Artes Visuais. E-mail: leonardoribeirobrandao@gmail.com. Orcid: https://orcid.org/0000-0001-9149-9609 Lattes: http://lattes.cnpq.br/6316082183433387

2 Antonio Vargas é Doutor em Artes pela Universidad Complutense de Madrid (1992), com pós-doutorado na Universitat de Barcelona (1996). Artista visual e professor do Programa de pós-graduação em Artes Visuais da UDESC na linha de Teoria e História das Artes Visuais. E-mail: acvargass@gmail.com. Orcid: https:/orcid.org/0000-0001-8458-3909 Lattes: http://lattes.cnpq.br/4196104133376187
\end{abstract}

R. Inter. Interdisc. Art\&Sensorium, Curitiba, v.7, n.1, p. 258 - 269 Jan.- Jun. 2020 
imaginary and analyze in detail some of the puzzles in the game. The authors also try to highlight that the high quality of the graphic reproductions of the works of Italy in the 15 th century seek to provoke and / or awaken in the players a familiarity with the themes of History and Art History referring to this period.

Keywords: Assassin’s Creed; Pathosformel; Renaissance; Virtual Museum; Art in games

RESUMEN: Diferenciando los conceptos de Arte para juegos, Gamearte, Artgames y Juegos de artistas, el artículo analiza la presencia de reproducciones de obras de arte del Renacimiento en el juego Assassin's Creed 2, y relaciona el uso de rompecabezas como una estrategia de los creadores que induce al jugador hacer un proceso similar al propuesto por el historiador Aby Warburg. Los autores establecen esta relación basándose en los conceptos de Gamearte y Arte para juegos, identifican anacronismos de imágenes, establecen relaciones entre la experiencia artística en el juego digital con otras historias y posibilidades del imaginario y analizan en detalle algunos de los rompecabezas del juego. Todavía tratan de resaltar que la alta calidad de las reproducciones gráficas de las obras de la Italia del siglo XV buscan provocar y / o despertar en los jugadores una familiaridad con los temas de Historia e Historia del Arte que se refieren a este período.

Palabras clave: Assassin's Creed; Pathosformel; Renacimiento; Museo virtual; Arte en games

\section{I- Arte para Games, gamearte, artgames e jogos de artistas:}

Com os avanços tecnológicos e o desenvolvimento das artes digitais, os games também passaram a explorar suas potencialidades artísticas nas últimas décadas. Podemos estabelecer como um marco desta transformação o desenvolvimento do game Space Wars na década de 60 no MIT (Massachusetts Institute of Technology) pelo estudante Steve Russel. Como afirma Ventureli:

A partir daquele momento o jogo eletrônico aproximou a cultura de massa com as descobertas e investigações científicas, abrindo a possibilidade de aplicar os conhecimentos desenvolvidos na área da Realidade Virtual em simulações. (VENTURELLI in CHAVES e VARGAS, 2016. p. 42).

Apesar da ampliação das capacidades gráficas de computadores e consoles ter aproximado as formas mais tecnológicas da arte (games, vídeos, projeções, etc), é importante ressaltar que a aproximação entre jogos e arte não é algo exclusivo da arte digital. Ainda com Duchamp víamos um interesse no jogo de xadrez enquanto obra. Conforme entrevistas citadas no artigo de Humble (1998), Duchamp considerava o xadrez como uma escultura mecânica, valorizando os aspectos mentais e plásticos do jogo.

A aproximação entre os jogos e o sistema das artes, portanto, é resultado de um processo de expansão das fronteiras daquilo que era tradicionalmente visto como arte a partir do movimento modernista e das vanguardas do início do século XX.

Como um desdobramento desta expansão temos a formulação do conceito de gamearte para analisar os jogos digitais, buscando estabelecer parâmetros e critérios para diferenciar jogos de massa para puro entretenimento, jogos que utilizam elementos artísticos e jogos que são concebidos como obras de arte propriamente ditas. Naturalmente, as diferenciações dos métodos possíveis de aproximação entre jogos e arte resultam em diferentes conceitos e aplicações práticas. Conforme proposto no livro Works of Game 
(2015), escrito pelo pesquisador do MIT (Massachusetts Institute of Technology), John Sharpe, estas relações podem ser classificadas a partir de três dinâmicas distintas.

A primeira, segundo Sharpe, seria a game art, cuja obra artística é realizada a partir de jogos digitais. Ela subverte a percepção cultural sobre os jogos enquanto uma forma de entretenimento para que sejam fruídos a partir de outros aspectos. É uma operação muito mais próxima da arte conceitual, se apoderando da affordance ${ }^{3}$ cultural já conhecida dos jogos para dar-lhes um novo sentido. Geralmente se utiliza de algum jogo já existente e conhecido como base para a obra, tal como o xadrez ou grandes franquias como Super Mario Bros.

Outra categoria são os art games. Esse tipo de obra é ligado ao movimento dos jogos independentes ${ }^{4}$ produzidos ao longo da primeira década dos anos 2000. São game designers que utilizam das propriedades próprias dos jogos (mecânica, desafios, objetivos e outras) para criar uma experiência de jogo mais expressiva, propondo reflexões acerca das grandes questões da humanidade.

Devido ao fato de ser um movimento protagonizado por produtores de jogos que se propuseram a explorar o terreno das artes, Sharpe os caracteriza como vanguardistas e conservadores ao mesmo tempo. Se, por um lado, buscavam produzir experiências significativas e que fugissem das "fantasias masculinas de poder" para introduzir um conceito como uma força determinante da obra, por outro apresentavam uma postura conservadora sob a ótica da arte contemporânea. Afinal, o contemporâneo buscava, justamente, se libertar da ideia de que é necessário passar uma mensagem única com a obra, a qual o espectador/jogador deve acessar em detrimento da autonomia de sua percepção.

Para fundamentar sua acepção da terceira categoria, a saber, jogos de artistas, o autor parte dos estudos de John Hospers (1981), o qual dedica parte de seus estudos à diferenciação da atitude estética, em contraponto à atitude prática e cognitiva. Para ele a apreciação estética depende de uma "observação pela observação", o mais distanciada possível das questões práticas e utilitárias e também do próprio conhecimento acerca do objeto. Por mais que este último possa favorecer a apreciação estética em determinados casos, em outros pode ser um fator inibidor da mesma. Em suma, idealmente, ele propõe que a verdadeira atitude estética se dá apenas por um observador quase "desinteressado" ou imparcial em relação a obra, de modo que sua percepção não seja subjugada por outros desejos secundários.

Naturalmente, as três categorias possuem relações estéticas que se comportam de maneiras diferentes, conforme explicitado a seguir. Ao apresentar estas noções de estética, o autor busca tornar mais evidente e detalhado o modo como essas diferenças se manifestam em cada uma delas.

Nesse contexto, John Sharpe apoia-se nos conceitos de estética fina e estética espessa ${ }^{5}$ propostos por Hospers: "Estética fina é aquela que se concentra apenas nos valores formais de uma obra, enquanto estética espessa é aquela que leva em conta o lugar do trabalho em contextos culturais mais complexos." (SHARPE, 2015. p. 77)

Em outras palavras, a estética espessa tem uma relação direta com o âmbito da experiência, levando em consideração como o meio utilizado é útil para sua comunidade, bem como sua relação com o tempo e o espaço onde a obra se insere. Já a estética fina dá conta de uma percepção mais formalista da obra, levando em consideração aspectos como o traço e a relação entre formas e cores.

\footnotetext{
3 Termo oriundo do design, sem tradução exata na língua portuguesa. Trata-se da propriedade de determinado objeto que permite identificar sua funcionalidade sem necessidade de uma explicação prévia.

${ }^{4}$ Consideramos neste artigo que jogos independentes referem-se aos jogos produzidos por game designers que atuam fora das grandes empresas de entretenimento.

${ }^{5}$ No original, thin aesthetics e thick aesthetics, respectivamente.
}

R. Inter. Interdisc. Art\&Sensorium, Curitiba, v.7, n.1, p. 258 - 269 Jan.- Jun. 2020 
No caso das obras de game art, conforme definido acima, podemos considerar estética fina o uso da expressão simbólica - as formas e cores dos ambientes e dos personagens, bem como aquilo que o game representa para determinada cultura - dos jogos tomados como material formal para produção da obra. Esses aspectos são colocados a serviço da estética espessa que é a exploração conceitual proposta pelo artista, complexificando o papel do jogo no sistema das artes.

No caso dos artgames a própria criação do game é tomada como uma abordagem mais complexa do fenômeno cultural do jogo, portanto espessa, ao mesmo tempo que os aspectos conceituais surgem como elementos formais de sua estética, logo, fina.

Por sua vez, os jogos de artista buscam unir os aspectos da estética espessa de ambas as proposições acima, criando tanto o jogo em si, quanto complexificando a sua affordance para privilegiar suas questões conceituais que o aproximam do modo de operação típico das obras de arte.

Dito isso, podemos perceber que é possível operar artisticamente com os jogos de diferentes maneiras. Contudo, é importante compreender que existem diferenças entre o jogo produzido e utilizado como obra de arte e as obras/formas de arte utilizadas dentro de um jogo. É o que acontece na grande maioria dos jogos comerciais produzidos por grandes franquias. Geralmente, nesses casos "a questão artística se resume a ser arte para game e não arte como game” (CHAVES e VARGAS, 2016. p. 49).

Entretanto, isso não quer dizer que o material produzido terá menos qualidade ou terá prejuízos na experiência do jogo. É o que acontece na franquia Assassins Creed, da qual o jogo analisado faz parte. Apesar da função da arte no jogo estar mais próxima da "arte para game" do que como um elemento conceitual, sua utilização dentro da narrativa e mecânica do game propõe uma experiência que ultrapassa o mero entretenimento do jogo comercial.

A fim de evidenciar estes aspectos na franquia, analisamos o jogo Assassins Creed II e a presença de reproduções de obras de arte, principalmente do período renascentista, como parte importante da experiência proposta pelo jogo.

\section{II - Um passeio pela História da Arte renascentista em Assassin's Creed II:}

Assassin's Creed II é o segundo game da franquia Assassin's Creed, produzido pela empresa Ubisoft Entertainment. A narrativa da série de jogos trata do conflito entre duas ordens com objetivos opostos: de um lado existem os Assassinos buscando a paz através do livre arbítrio e do outro os Templários que buscam dominar o mundo controlando a humanidade através dos dispositivos chamados "pedaços do Éden". A partir deste pano de fundo, os diferentes jogos da série aproveitam momentos de conflitos históricos para inserir a participação destes grupos nestas situações, geralmente colocando as classes dominantes como aliadas aos Templários e os movimentos revolucionários ligados aos Assassinos.

O diferencial do game está no fato de ser um jogo de mundo aberto ${ }^{6}$ que permite ao jogador explorar recriações fiéis de lugares reais. No caso do Assassins Creed II temos a reprodução das grandes cidades italianas no século XV, tais como Veneza e Florença, e a participação interativa de figuras históricas,

\footnotetext{
${ }^{6}$ Conceito de game design para "jogos onde existe a liberdade para explorar, sem ordem linear, uma ampla série de lugares, e onde é possível, também sem ordem linear, cumprir missões não explicitadas ou impostas pelo jogo, permitindo ao jogador inclusive criar parâmetros próprios de desafio e vitória baseado na exploração dos elementos disponíveis, além de ter acesso a objetos e ações que permitem a customização do personagem" (BARBOSA, 2014. p. 16)
}

R. Inter. Interdisc. Art\&Sensorium, Curitiba, v.7, n.1, p. 258 - 269 Jan.- Jun. 2020 
como Leonardo Da Vinci, o qual tem um papel fundamental no desenvolvimento da narrativa junto ao protagonista.

Por mais que seja um jogo produzido para a grande indústria do entretenimento, o jogador tem a possibilidade de tornar o ato de jogá-lo como uma espécie de turismo virtual. Como parte da narrativa ele pode visitar monumentos e construções históricas e organizar galerias digitais que proporcionam a apreciação e descoberta de obras consagradas na História da Arte. Tudo de modo dinâmico, interativo e singular.

O cuidado com a reprodução de uma experiência análoga à realidade é tanto, que tal aspecto pode ser utilizado como uma forma diferenciada de proporcionar ao jogador um contato direto com temas da História e da História da Arte, servindo ao mesmo tempo como instrução e fruição através de um acesso facilitado pelo meio digital. Não obstante, há uma percepção por parte de estudantes que jogaram este jogo como se já tivessem experienciado estas cidades e obras ao entrar em contato com o tema em aulas de História da Arte. É o que relata Douglas N. Dow, professor de História da Arte na Kansas State University, em seu artigo chamado "Facetas Históricas: Anacronismo, Simulação e História da Arte em Assassin's Creed II" (2013). Tal motivo o inspirou a escrever sobre os "efeitos que o jogo pode ter na percepção de um indivíduo sobre os locais históricos representados no $A C$ II” (p. 216).

De fato, os locais são vários: ao longo da narrativa é possível visitá-los e conhecer suas obras, como a Basílica de São Pedro, Basílica de Santa Cruz e outros exemplos. Esses ambientes interativos e navegáveis, como é próprio da lógica de operação dos games, tornam esta visitação virtual em uma experiência que flerta com o real.

Segundo Donald Dow, essa afirmação é sustentada pelos estudos de Baudrillard. De acordo com sua lógica "essa imersão e controle da representação apaga a fronteira entre o meio e o real” (DOW, 2013. p. 218), gerando este efeito observado nos alunos que sentiam familiaridade com a Itália do século XV após jogarem o game.

Entretanto, ao mesmo passo em que é possível identificar o real na representação ficcional, esta simulação também apoia-se em certa estranheza e anacronismo. Nas representações das cidades italianas convivem monumentos e aspectos da época, junto com outros que vieram somente séculos depois, tal como nos caprichos arquitetônicos do século XVIII. Um exemplo disto é a representação da Basílica de San Lorenzo, onde "o perfil da Basílica de San Lorenzo é dominado no jogo (e na Florença de hoje) pela cúpula da Capella dei Principi, uma característica acrescentada à paisagem urbana no século XVII." (Id. p. 219)

Devido à fidelidade na representação gráfica das obras reais, bem como na própria constituição de uma galeria de arte virtual, podemos traçar paralelos também com a constituição de um Museu Imaginário conforme observado por André Malraux.

Malraux problematiza, em sua obra intitulada "O Museu Imaginário" (1947), a transformação que a institucionalização dos museus impôs sobre a relação entre espectador e obra de arte ao longo da história. Aponta também os avanços tecnológicos para a reprodução de imagens como um fator que transforma novamente esta relação, abolindo fronteiras espaço-temporais e permitindo a criação de museus como espaços mentais particulares e coletivos. O museu pode então se configurar como um espaço imaginário onde armazenamos um referencial de imagens maior do que qualquer museu poderia adquirir, abrigando formas da arte para que sobrevivam em nós através dos tempos.

Diferentemente do museu tradicional, o museu imaginário não tem limites: põe em confronto formas de um mundo informe e atemporal, informe e atemporal no sentido em

R. Inter. Interdisc. Art\&Sensorium, Curitiba, v.7, n.1, p. 258 - 269 Jan.- Jun. 2020 
que escapa ao mundo histórico. Na realidade, o museu imaginário descentraliza e desierarquiza a cultura. Não busca a totalidade (sempre impossível), mas permite que se completem suas lacunas. Embora sem conseguir em momento algum aproximar-se da totalidade, provoca o imaginário, capaz de concebê-la, e permite ainda pensar a reprodução como uma tentativa concreta, embora precária, de sonhá-la. (SILVA, 2002. n.p)

Dentro do game a ideia de um museu virtual é levada à literalidade: o jogador tem a possibilidade de coletar obras renascentistas e montar uma galeria particular. Essa galeria pode ser visitada a qualquer momento e permite a apreciação da reprodução fiel de quadros como: "O nascimento de Vênus" e "Primavera" de Botticelli; "Vênus adormecida" de Giorgione e outras 27 pinturas do Renascimento.

Nesse sentido, a reprodução das obras em Assassin's Creed é uma manifestação concreta de como a tecnologia permite acessar obras deslocadas de seu contexto original, tal como um museu. Além da questão da acessibilidade ampliada, esta justaposição também permite estabelecer novas relações entre as obras coletadas e observar a sobrevivências das formas,

\section{III- O pathosformel warbuguiano em Assassin's Creed II:}

Aby Warburg (1866 - 1929) propôs um novo modo de analisar a história da arte, especialmente a luz do seu conceito de pathosformel. Ele acreditava que a compreensão da arte deveria ir além de métodos puramente formalistas e estetizantes, acreditando que esta deveria se dar através de uma psicologia social mais ampla. Segundo Felipe Charbel Teixeira:

Seu interesse voltava-se precisamente para a análise das relações complexas entre o artista e seu meio, com destaque para aspectos como o papel do comitente na produção artística e a relação dos artistas com modelos literários circulantes, especialmente no que diz respeito ao exame dos mecanismos de transmissão e sobrevivência da memória cultural da Antiguidade. (TEIXEIRA, 2010. p. 138)

Charbel coloca que tal ideia é inicialmente desenvolvida nos estudos de Warburg sobre o Renascimento, especialmente sobre as deusas de Botticcelli, onde o historiador aponta a "mobilização inconsciente de forças emotivas (patéticas) herdadas do contato com a tradição antiga" (Id, p. 138). É o surgimento do conceito de "Pathosformel", que seria a "fórmula dos pathos", a qual se manifesta na história da arte através de formas que são repetidas e resgatadas ao longo da produção dos artistas como uma sobrevivência da memória cultural, emotiva e "energética" de aspectos da humanidade.

Ainda segundo Charbel, a teoria warburguiana alinha-se com a psicanálise do final do século XIX, como se essas formas que sobrevivem na arte trouxessem em si uma "energia psíquica" que suscita uma recordação de determinadas experiências primárias da humanidade.

Em seu método de análise, posteriormente concretizado na criação das pranchetas que compõem Bilderatlas Mnemosyne, Warburg reunia imagens que representassem a transmissão desses "engramas da experiência emotiva" e "patrimônios hereditários da memória" através das formas representadas. A sobrevivência das formas saltava aos olhos a partir da reunião anacrônica das forças temáticas que organizavam o Atlas, funcionando, nas palavras de Agamben, como:

Uma espécie de estação de despolarização e repolarização [...] em que as imagens do passado, que perderam seu significado e sobrevivem como pesadelos ou fantasmas, são

R. Inter. Interdisc. Art\&Sensorium, Curitiba, v.7, n.1, p. 258 - 269 Jan.- Jun. 2020 
mantidas em suspenso, nas sombras em que o sujeito histórico, entre o sono e a vigília, se confronta para lhes restituir a vida. (AGAMBEN, 2007. p. 36).

As semelhanças entre o método warburguiano de historiografia da arte e as imagens da arte renascentista em Assassin's Creed II podem ser observados através dos desafios que fazem parte das missões disponíveis para exploração da narrativa. Ao longo do mapa do jogo estão escondidos alguns "glifos", que representam fragmentos de dados encriptados contendo partes importantes da "verdade", envolvendo os conflitos entre assassinos e templários, a história da humanidade e a busca pelos "pedaços do Éden".

Como os dados estão encriptados, o jogador precisa resolver um enigma para que possa liberar o acesso à informação. Estes enigmas, geralmente envolvem obras de arte, buscando encontrar semelhanças em suas formas, temas e até mesmo forçando o jogador a manipular a obra como um quebra-cabeça, a fim de reconstituir a imagem correta. Vamos ilustrar esta afirmação com uma situação concreta.

$\mathrm{Na}$ imagem a seguir temos o exemplo do primeiro desafio. Para coletar a primeira parte da informação desta "verdade", o jogador deve analisar as obras e encontrar semelhanças que formam o grupo das 5 que correspondem à resposta correta. Nesse caso, temos a dica no próprio enunciado: o verbo "apanhar" aparece destacado em vermelho, fornecendo a pista inicial. Depois, cabe ao jogador observar as imagens para encontrar a repetição do elemento formal "fruto/maçã", o qual traz em si grande valor simbólico e é uma forma sobrevivente ao longo da história da arte.

Neste grupo estão reunidas obras de Hugo Van der Goes (1439), Guido Reni (1620), Peter Paul Rubens (1638) e J. Doyle Penrose (1890).

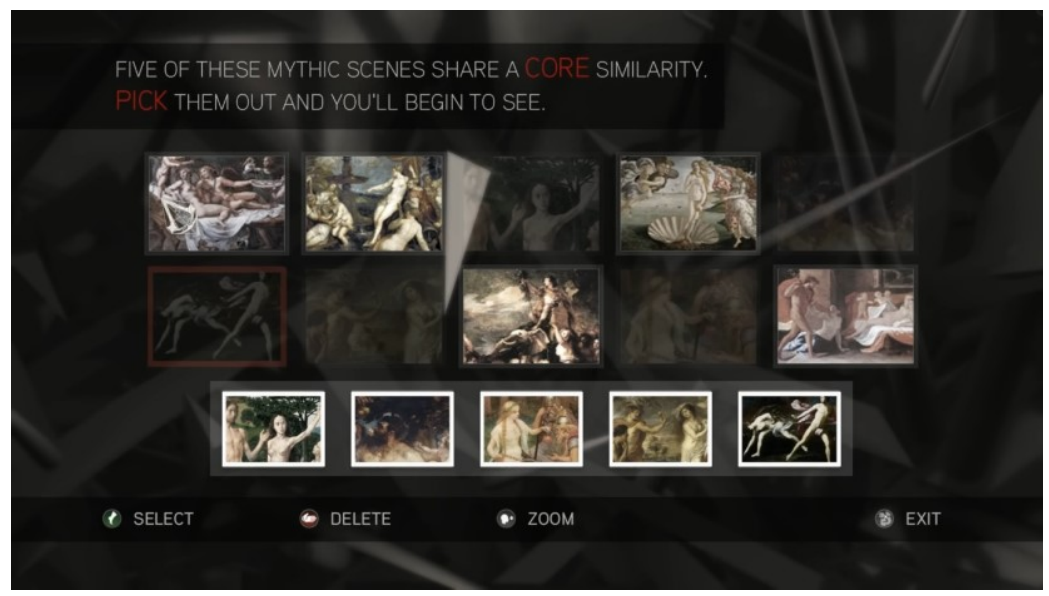

Figura 1 - Captura de tela do jogo Assassin’s Creed II

Podemos ver que aqui estabelece-se uma justaposição anacrônica de imagens que extrapola o próprio período retratado no jogo. Contudo, sem perder a coerência com a narrativa que está sendo desenvolvida: metaforicamente a maçã é o símbolo do pecado original, do desafio, do conhecimento e da "verdade".

Também observamos, conforme a escolha das imagens, a manifestação do mesmo "atrito oriundo da coexistência de duas concepções de mundo distintas, entretanto, não antagônicas" (TEIXEIRA, 2010) entre as culturas pagãs e a cultura cristã que permeavam o espírito de época renascentista. A primeira pela profunda admiração dos intelectuais e artistas pela antiguidade pagã e a segunda pela predominância da visão de mundo cristã dos séculos XIV, XV e XVI. Ambos os temas aparecem representados nas obras, bem como também há uma sobrevivência do fruto nas diferentes culturas. 
A primeira obra faz referência à mitologia e cultura cristã. Trata-se da obra do pintor flamengo Hugo Van der Goes, chamada “The Fall of Man” (1439). Nela temos a representação de Adão e Eva no Éden. $\mathrm{Na}$ obra eles são tentados por uma besta antropomórfica a desobedecer às ordens de Deus: não tocar no fruto proibido.

A cena representa o momento exato em que Eva, após já ter decidido cometer o pecado, como podemos ver pela maçã que já segura em sua mão esquerda, colhe outra maçã e convence Adão a pecar também, tornando-se a responsável pela "queda do homem".

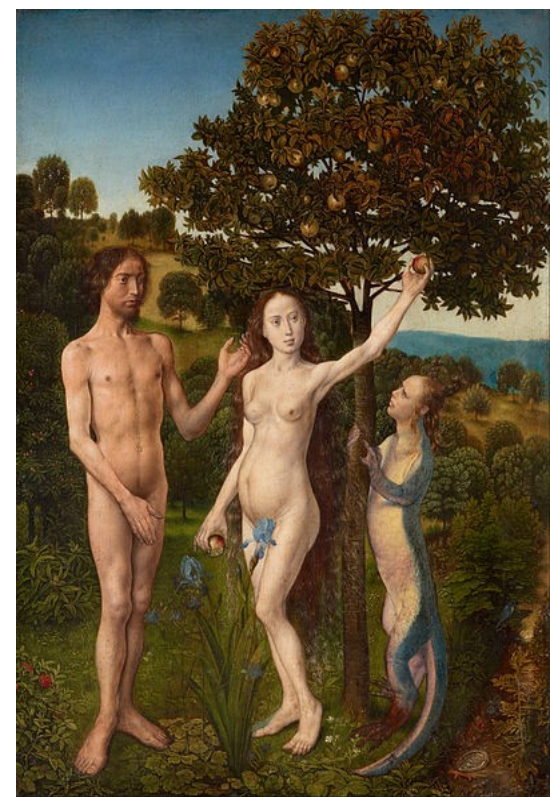

Figura 2 - The Fall of Man - Hugo Van der Goes (1439). Óleo sobre tela.

Já na segunda obra temos uma representação que não diz respeito a mitologia cristã, mas sim de uma história grega. Nela é contado o mito de Atalanta: uma poderosa e ágil guerreira que casaria apenas com o homem que a derrotasse em uma corrida. Como tal feito parecia impossível, Hipomenes pede ajuda a Afrodite, que lhe oferece 3 maçãs douradas para que derrube ao longo da corrida contra Atalanta. Deslumbrada pela beleza dos frutos, Atalanta para de correr para juntá-los e perde. Ela então é obrigada a casar com o homem, desafiando assim uma profecia divina que dizia que a guerreira seria amaldiçoada no matrimonio e que termina por ocasionar a transformação de ambos em leões.

Novamente, temos a relação entre uma mulher que recolhe um fruto que é quase uma armadilha divina e acaba por desgraçar a vida de um homem. 


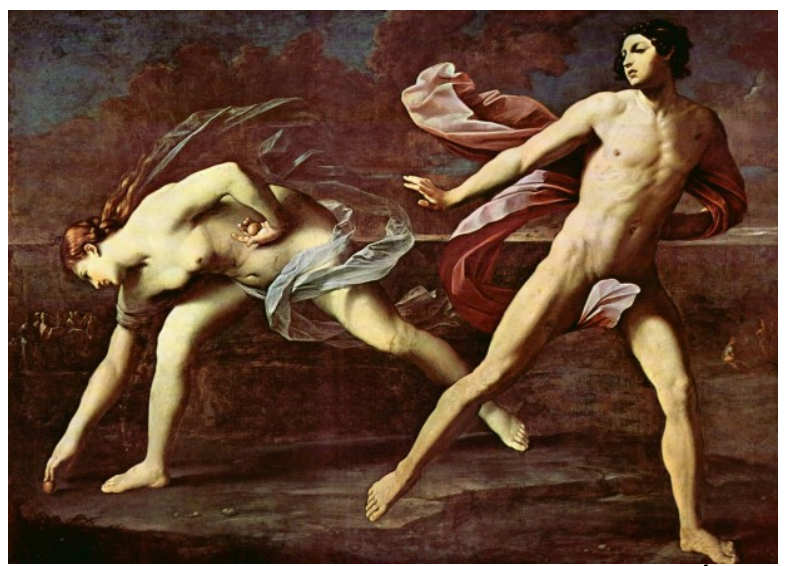

Figura 3 - Atalanta and Hippomenes - Guido Reni (1620). Óleo sobre tela.

Nas duas obras acima, podemos observar o cuidado com a representação das formas e volumes, perseguindo o ideal de captar o movimento próprio da vida. Como observa Warburg:

No século XV, a "Antiguidade" não exigia dos artistas que abdicassem incondicionalmente das formas de expressão adquiridas mediante suas próprias observações - como exigiria o século XVI, quando a matéria antiga foi encarnada à maneira antiga - , mas apenas chamava a atenção para o mais difícil problema das artes plásticas: como capturar as imagens da vida em movimento. (WARBURG, 2015. p. 51)

A seguir temos duas obras do mesmo artista, Peter Paul Rubens, representante do barroco flamengo marcado por seu estilo extravagante, cheio de dramaticidade, intensidade e sensualidade. As obras de Rubens que trazem esta sobrevivência são:
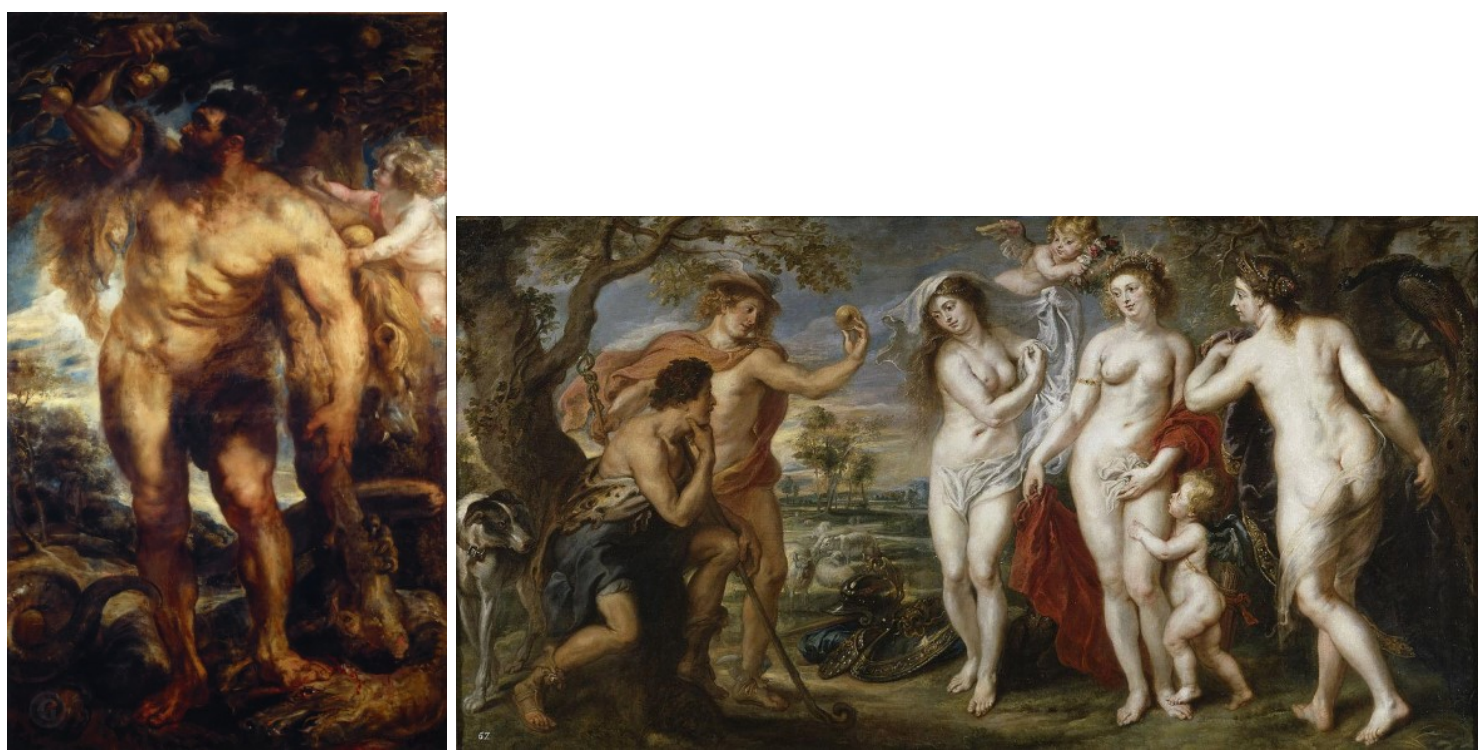

Figuras 3 e 4 - Hercules in the Garden of the Hesperides e The Judgement of Paris - P. P. Rubens (1638) . Óleo sobre tela.

Novamente, as obras remetem à mitologia grega e suas histórias. Na primeira obra temos o mito de Hércules, que recebe as maçãs douradas como um prêmio de Atlas por ajudar a salvar suas filhas Hesperides. Por mais que a cena retratada seja uma cena de vitória, as pinceladas mais brutas e a predominância de sombras na obra dão a ela um caráter mais dramático, próprio do Barroco. 
Característica que fica menos aparente na obra do Julgamento de Paris, onde a nudez e a iluminação da representação das deusas Vênus, Minerva e Juno pretende retratar a beleza, contrastando com os humanos retratados no lado esquerdo. Apesar das cores mais leves, o pomo representado neste mito é o escolhido por Paris, que, ao preferir a belíssima Helena, ocasiona a guerra de Tróia e toda sua tragédia. Mais uma vez o homem é seduzido pelo fruto oferecido por uma figura feminina e incorre na falha trágica em função disto.

Por último, o game traz uma obra de séculos à frente do tempo em que a narrativa se passa: uma obra do século XIX do pintor irlandês James Doyle Penrose. Escapando de referenciais mais óbvios na história da Arte, como a tradição cristã e a antiguidade clássica, esta obra apresenta uma cena da mitologia nórdica, representando a deusa Idun.

Idun é uma divindade feminina associada às maçãs, à juventude e à poesia.

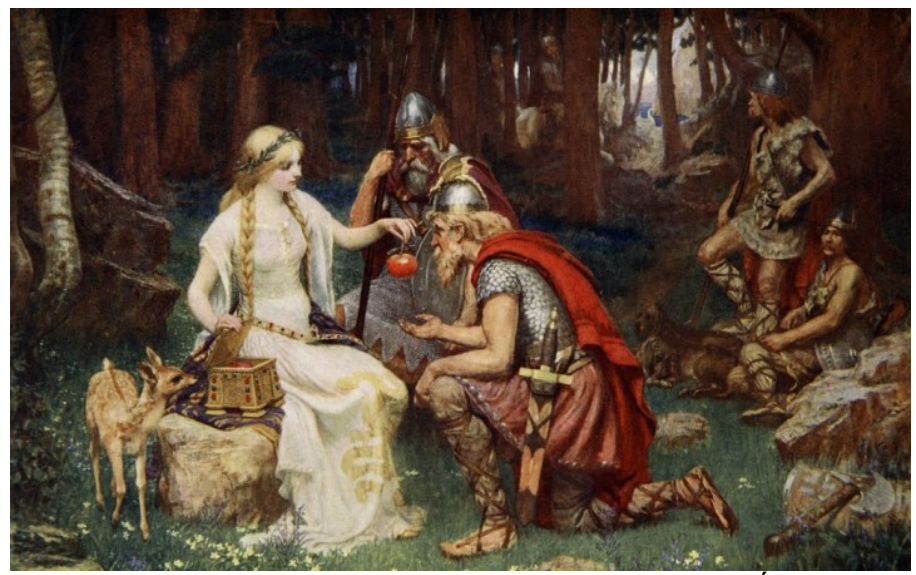

Figura 5 - Idun and the apples - J. Doyle Penrose (1890). Óleo sobre tela.

Suas maçãs ofereciam aos mortais a juventude eterna e a imortalidade aos deuses, que recebiam uma maçã por dia de seu pomar encantado. O gesto de entregar a maçã, neste caso, parece puramente benevolente, como sugerem a predominância do branco com o qual a deusa é retratada, bem como seu semblante sereno e a tranquilidade da gazela que se aproxima sem medo.

Podemos reparar que o fruto sobrevive como uma metáfora que sempre apresenta um movimento: ele é colhido, dado ou recebido, num processo eterno de transferência entre duas instâncias, ora tratado para o bem, ora para o mal.

Tal interpretação simbólica do fruto se relaciona diretamente com a narrativa do game: é coletando estes "fragmentos do Éden" - representados pelo fruto - que o protagonista recupera o conhecimento acerca da história do mundo para resolver o conflito entre assassinos e templários.

Em algumas obras, inclusive, é inserido o próprio "fragmento do Éden" dentro da obra original, aproveitando-se de obras que, apesar de não terem o fruto representado em sua forma verdadeira, trazem gestos e formas que possam remeter ao tema de apanhar a maçã. Como, por exemplo, em alguns dos 20 desafios de glifos: 


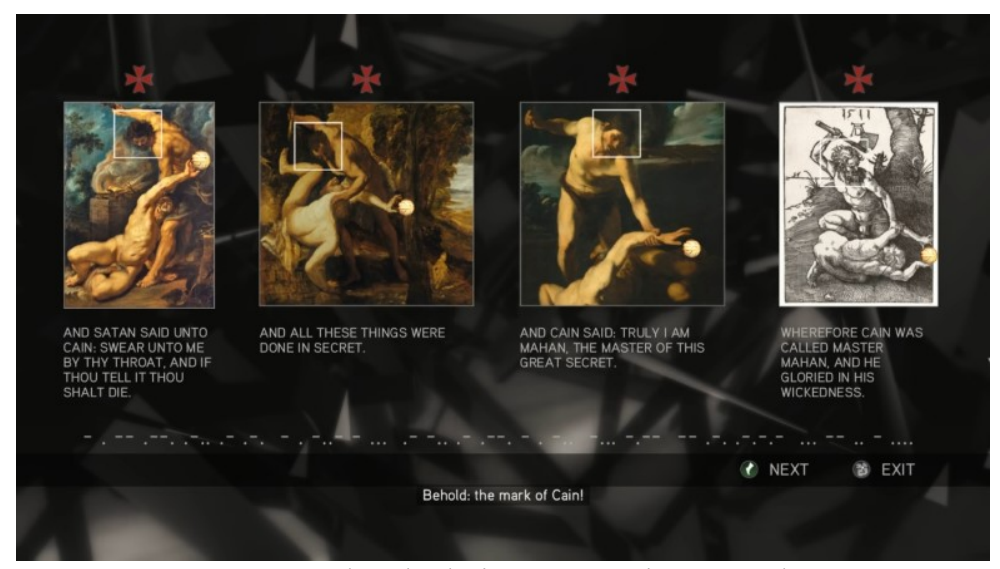

Captura de tela do jogo Assassin's Creed

Primeiro o jogador resolve um quebra cabeça e manipula pedaços da obra para reconstruir sua forma original, depois ela modifica-se e o "fragmento do Éden" aparece inserido na imagem (o círculo amarelo que se destaca na imagem), criando novos significados, releituras e relações entre obras a partir da intervenção dos game designers.

\section{Considerações finais}

É possível afirmar que Assassin's Creed II pode servir como um dispositivo para acessar questões próprias do campo das artes. Primeiramente, pela qualidade da representação gráfica dos ambientes, personagens e das próprias obras, numa demonstração de domínio da execução da técnica própria da arte digital. Depois, porque articula o tema da obra (uma espécie de viajante temporal que revive o passado a partir das memórias de outro) e o suporte de produção (a partir de um game digital que apresenta uma experiência navegável e interativa com ambientes e elementos importantes na história da humanidade).

Por mais que o game não se proponha a apresentar ao jogador uma experiência artística, tal qual uma obra de galeria, ele permite que o jogador se coloque como espectador de um museu digital ou ainda, como participante de uma espécie de turismo virtual através da narrativa.

Ainda é válido ressaltar que nos próprios desafios que fazem parte da jogabilidade estão operações próprias das artes visuais, como apresentado nos desafios dos glifos. O jogo propõe ao jogador que olhe para as obras de modo diferente, desenvolvendo um olhar analítico e estético que resulta num processo de apreciação das obras em um nível mais profundo que o olhar ordinário.

É justamente pela pertinência destes aspectos que o jogo também pode servir ao ensino de História da Arte. Para isso é preciso conte com uma mediação que valorize e chame a atenção para estes aspectos.

Pelo fato de ser direcionado para a grande indústria dos jogos pode até ser que o jogo não se enquadre nas definições de gamearte conforme vimos na primeira seção. Entretanto, é inegável que todos os elementos citados neste artigo têm o potencial de despertar uma atitude de apreciação estética (ou até cognitiva) acerca das grandes obras que compõem a História da Arte, para além da mera apreciação prática e/ou lúdica, semelhante ao abordado nos estudos de Hospers.

Assim, o jogo apresenta um diferencial quando comparado a outras grandes franquias do mercado, de modo que pode ser perfeitamente utilizado dentro de nosso campo de conhecimento. 


\section{Referências bibliográficas:}

AGAMBEN, G. Ninfe. Torino: Bollati Boringhieri, 2007.

BARBOSA, R. C. G. Jogando com a cidade: A construção das ações no espaço urbano nos jogos digitais de mundo aberto "Bioshock" e "Grand Theft Auto IV" Tese (Graduação em Comunicação Social) Universidade Federal de Minas Gerais - Ufmg, Belo Horizonte, 2014. Disponível em: $<$ http://hdl.handle.net/1843/BUBD-A97FXV>. Acessado em: 08 fev. 2020.

BEARDSLEY, M. C.; HOSPERS, J. Estética: Historia y fundamentos. 4. ed. Madrid: Cátedra, 1981.

CHAVES, C. G. V. e VARGAS, A. C. Gamearte - Uma linguagem poética in DAPesquisa, v.11, p. 40 - 52, ago/2016. Disponível em: https://tinyurl.com/y2mamldv. Acessado em: Abril/2018

DOW, D. N. “Historical Veneers: Anachronism, Simulation, and Art History in Assassin's Creed II.” In Playing with the Past: Digital games and the simulation of history, edited by Matthew Wilhelm Kapell and Andrew B. R. Elliot, , 2013. p. 215-231.

MALRAUX, André. Le Musée Imaginaire. [Paris]: Gallimard, imp. 2008. Publicação original: 1947.

SHARP, J. Works of Game: On the aesthetics of games and art. United States Of America: Mit Press, 2015.

SILVA, E. O Museu Imaginário e a difusão da cultura in Revista Semear, v. 6, PUC-RJ. 2006. Acesso em: https://tinyurl.com/y48atfup. Acessado em Julho de 2019.

TEIXEIRA, F. C. Aby Warburg e a pós-vida das pathosformel antigas. História da historiografia. Ouro Preto, v-1, n 5, p. 134-147, setembro . 2010.

WARBURG, A. Histórias de Fantasmas para gente grande. Tradução de Lenin Bicudo Bárbara. São Paulo: Companhia das Letras, 2015. 